\title{
Evaluating the Impact of a Pilates Intervention on Physical Function in Children with Hypermobility Spectrum Disorder: A Study Protocol Using Single-Case Experimental Design
}

\author{
Elizabeth A. Hornsby ${ }^{1,2 *}$, Leanne M. Johnston ${ }^{1}$ \\ ${ }^{1}$ School of Health and Rehabilitation Sciences, The University of Queensland, Brisbane, Australia \\ ${ }^{2}$ Kids Care Physiotherapy, Brisbane, Australia \\ Email: *e.hornsby@uqconnect.edu.au
}

How to cite this paper: Hornsby, E.A. and Johnston, L.M. (2021) Evaluating the Impact of a Pilates Intervention on Physical Function in Children with Hypermobility Spectrum Disorder: A Study Protocol Using Single-Case Experimental Design. Open Journal of Pediatrics, 11, 55-70. https://doi.org/10.4236/ojped.2021.111006

Received: January 10, 2021

Accepted: March 5, 2021

Published: March 8, 2021

Copyright $\odot 2021$ by author(s) and Scientific Research Publishing Inc. This work is licensed under the Creative Commons Attribution International License (CC BY 4.0).

http://creativecommons.org/licenses/by/4.0/ (c) (i) Open Access

\begin{abstract}
Background: Pilates has been shown to be an effective intervention for adults with musculoskeletal conditions with only a few examples available in the literature for children. As musculoskeletal pain is a major symptom experienced by children with Hypermobility Spectrum Disorder (HSD), they may benefit from practicing Pilates to improve postural alignment, strength and motor control to effectively distribute movement load and decrease adverse load through involved joints. Method: This study aims to evaluate the impact of a Physiotherapy-led Pilates intervention on school aged children with HSD and the benefits of this approach on pain, physical function and quality of life when delivered in a community-based model of care. A single-case experimental design (SCED) that incorporates a multiple baseline design will be used. Children with HSD, aged from 8 to 12 years, will commence concurrently in this study. Participants will undergo multiple assessments through all phases of the study which incorporates an A-B-A withdrawal design. The initial baseline period will be randomised from 5 to 7 weeks duration, then participants will enter the intervention period for 8 weeks followed by a withdrawal period of 5 weeks. The Physiotherapy-led Pilates intervention will consist of individual, 45 minute bi-weekly sessions, performed on both mat and the Pilates Reformer with an additional home program of mat exercises performed weekly. The study hypotheses are that children will show: 1) a decrease in pain; 2) an increase in their physical function as measured by muscle strength, postural control, fatigue and physical activity levels; and 3) an
\end{abstract}


improvement in their Health Related Quality of Life in the domains of physical, emotional, social and school functioning. Conclusion: The findings will add specific responsiveness information to the scientific evidence for Physiotherapy-led Pilates for children with HSD.

\section{Keywords}

Pilates, Pain, Physical Function, Hypermobility, Children

\section{Introduction}

Hypermobility Spectrum Disorder (HSD) has been described as "a condition characterized by generalized joint hypermobility (GJH) in association with chronic joint pain in the absence of a known genetic disorder" [1]. This condition was previously referred to as Benign Joint Hypermobility Syndrome (BJHS) or Joint Hypermobility Syndrome (JHS) but in 2017 an international consortium of world experts recommended the term be replaced with HSD [2]. Joint hypermobility is defined as the capability of a joint to move passively and/or actively beyond normal limits along physiological axes and when hypermobility is present in multiple joints the term GJH is preferred [2]. The Beighton Score (Table 1) is the most accepted clinical method for identifying GJH and has been shown to be a valid measure in primary school aged children [3]. Hypermobility has been reported to be more prevalent in girls than boys [4] [5], in younger children than older children [1] and ethnic groups such as Asian and African populations [6].

The diagnosis of HSD is made with the Revised (Brighton 1998) Criteria [7] which involves either 2 major criteria of multiple hypermobile joints in combination with arthralgia in multiple joints, or a combination of major or minor criteria involving other systems such as the skin, eyes and cardiovascular system (Table 2). The prevalence of GJH and thus HSD has been variable reported. To give some indication, an Australian cohort study by Morris [5] assessed 1584 participating 14 year old children with the traditional cut-off threshold of $\geq 4$ hypermobile joints on the Beighton Score which found $48 \%$ presented with hypermobility whereas with a more rigorous cut-off of $\geq 6$ hypermobile joints, the prevalence was $18.6 \%$. As studies reporting the prevalence of GJH have not documented the exact number of pain areas, there is insufficient detail to determine the number who could have been diagnosed with HSD.

Children with HSD experience a range of chronic musculoskeletal symptoms including pain in joints or surrounding muscles and soft tissue, joint instability, fatigue and reduced muscle strength, endurance, proprioceptive acuity, balance, motor co-ordination and exercise tolerance. All these factors impact on their functional activity and participation which can lead to poorer health outcomes and psychological issues. 
Table 1. The Beighton Score. (as described by Smits-Engelsman in the appendix of Beighton Score: a valid measure for Generalized Hypermobility in children 2011 [3]).

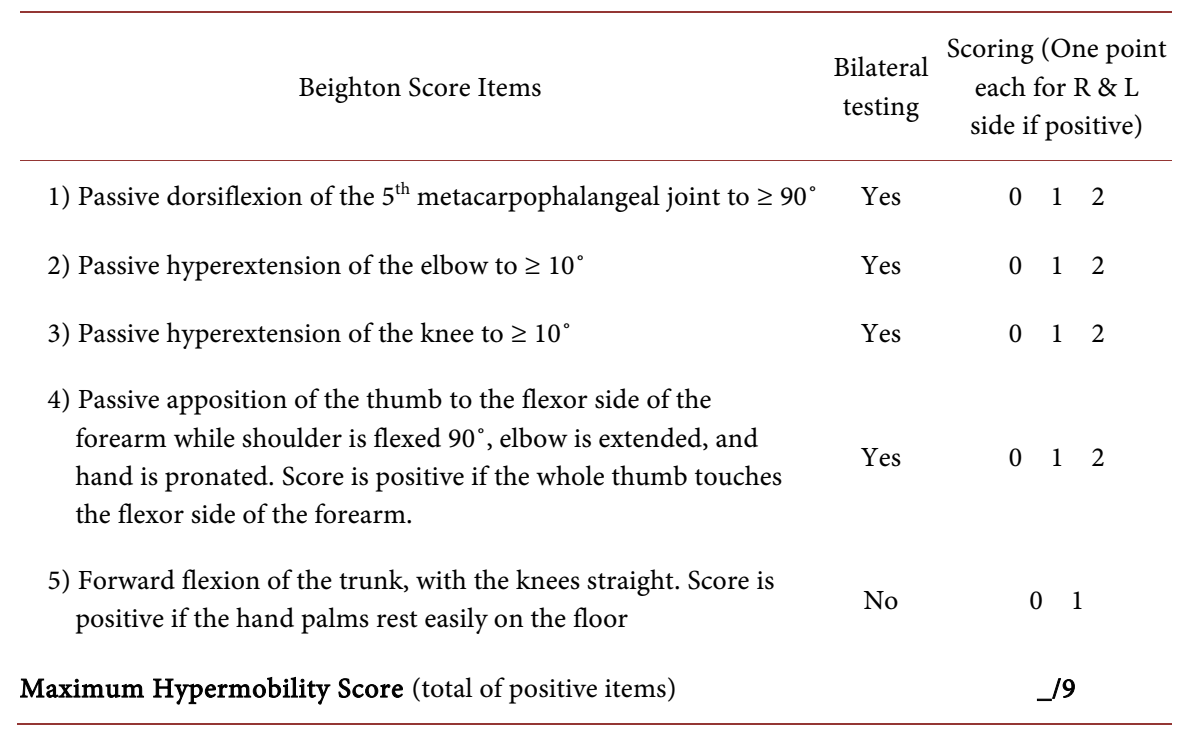

Table 2. Revised (Brighton 1998) Criteria. (As presented in the Revised (Brighton 1998) Criteria for the Diagnosis of Benign Joint Hypermobility Syndrome by Grahame 2000 [7]).

\section{Instructions for applying Criteria}

The BJHS is diagnosed in the presence of 2 major criteria, or one major and 2 minor criteria, or 4 minor criteria. Two minor criteria will suffice where there is an unequivocally affected first-degree relative. BJHS is excluded by presence of Marfan or Ehlers-Danlos syndrome [other than the EDS Hypermobility type (formerly EDS III) as defined by the Ghent 1996 and Villefranche 1998 Criteria, respectively]. Criteria Major 1 and Minor 1 are mutually exclusive, as are Major 2 and Minor 2.

\section{Major Criteria}

1) A Beighton Score of $4 / 9$ or greater (either currently or historically)

2) Arthralgia for longer than 3 months in 4 or more joints

\section{Minor Criteria}

1) A Beighton score of 1,2 or $3 / 9(0,1,2$ or 3 if aged $50+)$

2) Arthralgia ( $\geq 3$ months) in 1-3 joints or back pain ( $\geq 3$ months), spondylosis, spondylolysis/spondylolisthesis

3) Dislocation/subluxation in more than 1 joint, or in one joint on more than one occasion.

4) Soft tissue rheumatism $\geq 3$ lesions (e.g. Epicondylitis, tenosynovitis, bursitis).

5) Marfanoid habitus (tall, slim, span/height ratio $>1.03$, upper: lower segment ratio $<0.89$, arachnodactyly [+ Steinberg/wrist signs].

6) Abnormal skin: striae, hyper-extensibility, thin skin, papyraceous scarring

7) Eye signs: drooping eyelids or myopia or antimongoloid slant

8) Varicose veins or hernia or uterine/rectal prolapse

\subsection{Pilates Intervention}

Pilates was developed by Joseph Pilates in the 1920's as a series of exercises based on his guiding philosophy of achieving good health by coordination of body, mind and spirit. Into this method he called "Contrology" [8], he incorporated his traditional principles as defined by Wells [9]: 1) Concentration-the cogni- 
tive attention required to perform the exercise, 2) Centering-tightening of the muscular center of the body or "powerhouse" located between the pelvic floor and the ribcage during exercise [10] [11], 3) Control of movement by exerting the minimum of effort required, whilst maintaining posture and alignment, 4) Flow-the smooth transition of movement within the exercise sequence, 5) Precision or accuracy of the exercise technique and 6) Breathing correctly to promote relaxation and release tension whilst providing a rhythm of movement to assist coordination. During Pilates, lateral and posterior expansion of the rib cage is emphasized during inhalation as it facilitates maintaining abdominal contraction throughout the exercises [9] [12].

Joseph Pilates was ahead of his time in his approach to well-being and in his creation of exercises and equipment as described in his book "Return to Life Through Contrology" in 1945. He described "the Powerhouse" of the body as a cylinder of muscular support in the center of the body which includes the pelvic floor, diaphragm, abdominals and back extensors. Scientific research has now substantiated much of what Pilates advocated including recruiting the deep muscles of the pelvis and trunk. The basis of practicing Pilates is to use the mind to concentrate and recruit core muscles especially the transverse abdominus ( $\operatorname{TrA}$ ) before commencing an exercise. Since the 1990's, research has confirmed that contraction of the TrA occurs before movement of a limb and has an important effect on stabilization of the trunk [13] [14]. This activation of deep stabilizing trunk muscles (core stabilization) is integral in supporting the lumbar spine and pelvis which aides in decreasing chronic low back pain [15].

Over the years several approaches to the practice of Pilates have emerged, some have preserved his work and intent more than others. Classical Pilates still follows his original instruction of maintaining a "flat back" (posterior pelvic tilt) whereas the more modern Pilates has changed small elements of his work such as to focus on a "neutral spine" as new research has been conducted [9] [16] but for a program to be called "Pilates", the method must embody his overall philosophy and approach.

Pilates exercises can be performed on the floor using body resistance, referred to as mat-based Pilates or on uniquely designed Pilates equipment including the "Reformer", "Wunda Chair" and "Cadillac" which condition the whole body, using movements and positions that simulate functional activities, whilst correcting body alignment and balance. His extensive repertoire includes hundreds of exercises, that can be progressed from basic to an advanced level on each piece of equipment whilst allowing the instructor to increase load by using gravity or adjustable spring resistance and progressively select exercises that gradually increase motor control complexity or challenge. His method instinctively gained similar results to current resistance training research which shows resistance training leads to improvement in motor performance by increasing characteristics of strength, speed and power [17]. Resistance training is supported by the 2014 International Consensus Position Statement on youth resistance 
training [18], if it is designed and instructed by a qualified professional with prescription based according to training age, motor skill competency, technical proficiency and existing strength levels, at the appropriate intensity and volume whilst providing a safe, effective and enjoyable program.

The Pilates approach provides potential benefits for exercise motivation and safety for children and a physiotherapist designed and instructed Pilates Intervention can meet the goals of individual children. First, Pilates includes a wide variety of exercises that can be used to focus on key areas, or an affected joint. Second, for individuals with chronic conditions, Pilates can provide an interesting full body workout to strengthen and maintain multiple body areas simultaneously over the long term. Third, older children and youth can also benefit from specialized Pilates equipment, such as the reformer, which provides a safe option for growing bodies by using body resistance to increase strength. Fourth, many of the exercises are closed chain exercises which assist with improving joint proprioception and muscle control.

Previous studies have shown that Pilates does appear to be an effective intervention for children and youth with improvements noted in flexibility, muscle strength, postural orientation and balance, musculoskeletal alignment, pain levels, function and Health Related Quality of Life (HRQoL) in children [19]. Pilates has been reported to have many positive effects in reducing pain which has been well illustrated in adult populations [20], as well as a few examples in children [21] [22]. As musculoskeletal pain is a major symptom experienced by children with HSD [23], they may benefit from practicing Pilates to improve postural alignment, strength and motor control to effectively distribute movement load and decrease adverse load through involved joints. It has been demonstrated that a physiotherapist-led exercise program is significantly effective in reducing pain, improving HRQoL and increasing muscle strength in children with HSD and knee pain [24].

In a systematic review of the Effect of Pilates Intervention on Physical Function of Children by Hornsby in 2019 [19], there was wide variation seen in the structure and dose of the Pilates Intervention. Most were group based and involved specialized Pilates equipment with the Reformer being the most common. The number of exercises ranged from 15 to 27 with repetitions ranging from 5 to 10. Session duration ranged from 30 - 60 minutes, session number from 2 to 5 per week and length of intervention ranged from between 1 to 6 months with no follow-up of participants following conclusion of intervention reported in any study. A Delphi survey of Australian physiotherapists by Wells in 2014 [25] suggested that Pilates sessions for adults should be undertaken 2 - 3 times per week for 3 - 6 months and be supplemented by home exercises. This advice included individualised sessions for the first 2 weeks followed by group sessions of up to 4 clients per therapist. This may differ for children whose concentration levels and ability to maintain postural alignment and technical competency independently, safely and effectively may vary, requiring individual su- 
pervision for longer especially if they experience chronic pain. The use of specialized equipment such as the Reformer has been recommended for adults with chronic Low Back Pain [25] [26] so should also be researched in children. Also reported in the systematic review, only one of the Pilates instructors was a physiotherapist, but was for a group of children with a chronic musculoskeletal condition, Juvenile Idiopathic Arthritis, where the focus was on decreasing musculoskeletal pain and improving joint range, stability and function to improve HRQoL [21].

As children with HSD present with complex issues, they are challenging to manage effectively. Physiotherapists with their underlying knowledge of joints, muscles and movement including management of pain, are ideally placed to direct physical interventions for management of this condition. With comprehensive training in Pilates, it becomes a time effective treatment for physiotherapists, as it simultaneously treats different symptomatic areas, whilst been able to monitor the child's medical signs and symptoms. As Pilates can be instructed on an individual basis, this allows the child to correctly learn specific muscle activations and techniques that can be customized to focus on specific problem areas through choice of exercise and equipment so load and complexity can be progressed appropriately.

\subsection{Study Aims}

Based on the background literature, several potential benefits of Pilates have been reported in children [19]. The aims of this study is to evaluate the effects of a Physiotherapy-led Pilates program for school aged children with Hypermobility Spectrum Disorder (HSD) and the relative benefits of this approach on pain, physical function and quality of life when delivered in a community-based model of care. The study hypotheses are that children will show: 1) a decrease in pain; 2) an increase in their physical function as measured by muscle strength, postural control, fatigue and physical activity levels; and 3) an improvement in their HRQoL in the domains of physical, emotional, social and school functioning. These improvements will be maintained for a period of at least 3 months following the intervention.

\section{Methods}

\subsection{Study Design}

This study involves a Single Case Experimental Design (SCED) which provides an alternative approach to the traditional model and allows conclusions to be made regarding the effect of treatment based from the response of a single patient under controlled conditions, rather than group averages and broad generalizations. This will allow a small number of participants who act as their own control, to be studied in greater detail while still providing Level II scientific evidence [27], if specific criteria are met in the SCED design. Three factors which need to be incorporated are: 1 ) at least 3 phases in the study; 2) a multiple 
baseline design (MBD) for introduction of treatment and 3) repeated measures throughout each phase. Repeated measures of at least 5 data points are required in each phase to evaluate stability or variability of the response [27] [28] and to assist with observing trends and patterns in the data. SCEDs are more suitable for smaller cohorts that are more readily available, which require intensive assessment and intervention by suitably qualified and experienced practitioners.

Level II scientific evidence will be achieved in this SCED study in the following manner. First, an A-B-A withdrawal design will be used where " $\mathrm{A}$ " refers to the baseline (non-treatment) phase, " $\mathrm{B}$ " the intervention (treatment) phase and

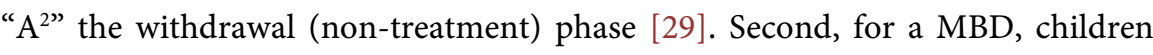
will be recruited to start in this study concurrently and will be randomised to commence at either 5, 6 or 7 weeks of baseline, followed by 8 weeks of intervention and 5 weeks of withdrawal. The minimum number of data points required in the baseline phases was chosen to minimize the burden on attendance by the family. It was proposed that at least 8 weeks would be required for the Pilates Intervention to allow for the lag time of when strength changes would be seen after introduction of the intervention and would be a practical intervention length for clinicians to fit into a school term. Third, the participants will undergo multiple weekly assessments through all phases of the study. This will be followed by one assessment at 3 months post the completion of the intervention to determine if any changes that are achieved during the intervention are maintained for this period. A blinded assessor who is also an experienced physiotherapist in the management of children, will perform the assessments and outcome measures and will not have knowledge of whether the child is participating in the baseline, intervention, or withdrawal phases.

\subsection{Ethics and Consent}

The study has been approved by the Human Research Ethics Committees at the Childrens' Health Queensland Hospital and Health service (HREC/17/QRCH/126) on the 08/08/17 and The University of Queensland (2017002017/HREC/17/ $\mathrm{QRCH} / 126$ ) on the $06 / 12 / 17$. All participants will sign an assent form and their parents an informed consent form.

\subsection{Participants}

Participants will be school aged children aged from $8<18$ years who meet the following criteria: 1) a score of $\geq 6$ on the Beighton Score (for hypermobility) (Table 1) and 2) history of at least four painful joints experienced at least $3 \mathrm{x} /$ week for a 3 month period in the last 6 months (for chronic pain) or meet other Brighton Criteria for HSD (Table 2). Children will be excluded if they have 1) other heritable disorders of connective tissue 2) other syndromes or significant complex medical or neurological conditions that may confound the outcomes 3) other intellectual impairment or behavioral disorders that would impact on ability to follow instructions and 4) have participated in a Pilates in- 
tervention in the preceding 6 months.

Nine children will be recruited in Brisbane, Australia through verbal advertisement and the intervention will be located locally in the community in a paediatric physiotherapy private practice. Throughout the study period including up to the 3 months post intervention measure, participants will not receive any physiotherapy or Pilates from another venue but will be able to continue their normal sporting activities.

\subsection{Procedure}

\subsubsection{Randomisation}

Concealed random allocation will be used and order of the participants will be generated by a person who is neither the physiotherapist assessing the outcome measures nor providing the Pilates intervention. A random series of numbers will be computer generated to correspond with the baseline duration of 5,6 or 7 weeks which will then be randomly allocated to the participant number (e.g. P1, P2, P3). Three participants will be allocated to either the 5, 6 or 7 week's group in the baseline period.

\subsubsection{Concurrent Multiple Baseline Design}

All participants will need to commence in the study concurrently, which will be provided for 45 minutes, 2 times per week for 8 weeks with a home program of 45 minutes also performed on one additional day under parental supervision. To comply with the MBD, the participants will be staggered into the Pilates intervention phase with participant 1 at week 6 , participant 2 at week 7 and participant 3 at week 8 . All participants will receive the same dose of intervention, so will continue to be staggered into the withdrawal phase with participant 1 at week 14, participant 2 at week 15 and participant 3 at week 16 for another 5 weeks of baseline measurements. There will be one final assessment at 3 months post the completion of the intervention at week 26,27 and week 28 respectively.

\subsubsection{Intervention-Content and Structure}

The Pilates program will be designed and delivered by the chief researcher who is 1) an experienced physiotherapist with over 30 years clinical experience in paediatric physiotherapy and 2) an accredited Pilates instructor for the past 15 years trained in the Body Arts and Science International (BASI) approach to the Pilates Method (Isacowitz 2014). The program will be individualized for each child and include a structured combination of Pilates exercises performed on mat and Reformer that will be provided at an appropriate level and age for each child. By only including exercises on the mat and Reformer, this program is designed to be accessible to other clinicians, who don't have to outlay the cost and space for fully equipped Pilates studio. The Reformer is an ideal piece of equipment for more basic exercises as they can be achieved with the trunk supported. Other small pieces of equipment such as a swiss ball and resistance bands will also be incorporated. 
The exercises focus initially on basic muscle activation and patterns of movement that are the essential basis of Pilates and as pain decreases and the child improves in strength, endurance, body awareness and confidence, they will be progressed to a more challenging level of difficulty. The frequency and length of the Pilates intervention of 45 minutes, 3 times per week is designed to meet the guidelines for physical activity and resistance training for children and youth [18] [30].

Each session will be divided into sections to focus on specific body areas: Section 1-Warm up (5 minutes) which prepares the body and is typically a selection of mat exercises that involves trunk movement; Section 2-Regional Muscle training (30 minutes) which focuses on all limbs whilst maintaining core stability and provides a complete body program using body resistance with mat work or spring resistance with the reformer; Section 3-Full body integration (5 minutes) which specifically works on body balance and co-ordination; Section 4Stretching and cool down (5 minutes) -incorporates specific stretches depending on the need of the individual and slow full trunk movements focusing on slow deep breathing.

At each session the Pilates instructor will record which exercises were performed, the number of repetitions, the equipment and amount of resistance used (number and colour of springs used on the reformer denotes whether mild, medium or heavy resistance). The parent will be invited to observe each session and given a personalised written home program to be performed once per week at home by their child under their supervision. The parent will sign the home program which will be returned at the next session so adherence can be monitored.

\subsection{Outcome Measures}

Outcomes will be measured across multiple levels of the International Classification of Functioning, Disability and Health (ICF: World Health Organisation 2007 [31]: 1) Physical-Body Functions and Structures a) Pain, b) Muscle strength, postural control and fatigue; 2) Performance-activity levels; and 3) Contextual-parent and child reported HRQoL.

The outcome measures to be performed weekly are:

1) Pain levels and descriptions with the PedsQL-Paediatric Pain Questionnaire (PedsQL PPQ) which will be the primary outcome measure [32] [33] using the Visual Analogue Scale (VAS) scale with both the child and parent reporting for their child's present pain and worst in past week where 0 indicates no pain and 10 the worst pain. In addition, the children will colour a body chart with the pain location, number of painful areas and intensity of the pain with the colour converted to a $1-4$ scale which will be totaled. The written pain descriptors by the participants will be classified in categories of a) global pain domains including quality, spatial, temporal, magnitude, effect, affect and covariate as used by Jensen in 2013 [34] and b) subdomains featuring the specific words or phrases used by the participants in this study. Frequency analysis for each participant 
will include a percentage of their totaled words calculated for each domain.

2) Muscle strength will be quantified with the Lafayette Hand-Held Dynamometer (HHD) System 01165. The test is performed with the clinician applying force to the required body part to overcome or "break" the participants resistance. The HHD provides the muscle strength readings as peak force in Newtons (N). The muscles groups that will be measured are hip extension, hip abduction, knee extension, shoulder external rotation, scapula adduction/downward rotation, elbow extension and wrist extension.

3) Postural control will be assessed with 3 items from the Kids-BESTest Balance Evaluation System [35]. Two items have been selected from the stability limits domain which are Functional Reach Forward (FRT-FWD) and Functional Reach Lateral (FRT-LAT) recorded in centimeters $(\mathrm{cm})$ and one item from the anticipatory domain which is Stand on one leg (SLS) recorded in seconds.

Two outcomes will be measured approximately monthly as both questionnaires refer to how the child was feeling for the previous month. These two measurements will be in the same week in each phase for participants which will account for the staggered start into the intervention phase required for the MBD. They will be given at week 1 and week 4/5 (P1), week 5/6 (P2), week 6/7 (P3) in the baseline phase; week $3 / 8$ and $7 / 8$ of the intervention phase; week $2 / 5$ and $5 / 5$ of the withdrawal phase and at the 3-month post intervention measure. All questionnaires will be completed independently by the participants, although assistance will be offered by the blinded assessor to explain the correct procedure and answer any questions. Both these tools have demonstrated good reliability and validity when used with children with various chronic conditions [36]. For both tools, with each domain and the total score, the participant is allocated a score of between 0 and 4 which are then reversed when converted to a score of between 0 - 100, with higher scores an indication of lower fatigue and higher HRQoL.

These measures are:

4) Fatigue levels with PedsQL Multidimensional Fatigue Scale (PedsQL Fatigue) [36] [37] which includes domains of general, sleep/rest and cognitive fatigue.

5) Health Related Quality of Life (HRQoL) with the PedsQL Paediatric Quality of Life Inventory (PedsQL 4.0) [37] which includes four domains of physical, emotional, social and school functioning.

The final measure will be performed in the last week of each phase:

6) Activity levels will be recorded with the Actigraph which will be worn during waking hours for 7 days at the end of each phase, with the child or parent recording in the diary, times of application and removal and what specific activities were performed in this time. To be considered representative, 4 valid days are required including at least 7 hours of data recorded per day and including one day on the weekend out of each 7 days [38].

All outcome measures will be repeated at the final 3-month assessment following intervention. 


\subsection{Data Analysis}

This SCED study incorporates an A-B-A design, where there is a baseline phase preceding and following the intervention. Experimental effect will be shown in this study if there is a change in the level or trend of an outcome measure when the participant commences the intervention or when the intervention is withdrawn [39] [40].

In addition, this study includes a MBD where several participants will commence concurrently into the baseline phase and will be measured simultaneously. The duration of the baseline will be randomized to 5 - 7 weeks and the participants will then be staggered over time into the subsequent intervention phase. This will then be followed by a withdrawal phase.

The most common approach to interpretation of data in a SCED study is visual analysis of graphic presentation where data is plotted against time [41]. Evaluation of the data will include visual examination for 1) level or the magnitude of performance at the start and end of a phase; 2 ) trend which refers to the direction of change within a phase and 3) slope which refers to rate of change within the data [40]. Other factors that need to be considered are variability of the data in phases, immediacy of intervention effect, data overlap and consistency of data patterns across similar phases [42]. A hypothetical example of this can be seen in Figure 1.

To substantiate visual findings, further statistical analysis will be explored using the two standard deviation band method [43] [44]. With this method the mean and standard deviation of data points within the baseline phase will be calculated and if at least two consecutive data points in the intervention phase fall outside the band then the changes will be considered significant [40]. This method will be employed when a participant transitions from $A^{1}$ to $B^{1}$ phase and from $B^{1}$ to $A^{2}$ phase and like visual analysis, allows each participant to have 2 opportunities to demonstrate experimental effect.

\section{Discussion}

This protocol paper describes the background and design of a SCED study which aims to evaluate the impact of a Physiotherapy-led Pilates program for school aged children with Hypermobility Spectrum Disorder (HSD) and the relative benefits of this approach on pain, physical function and quality of life when delivered in a community-based model of care. To our knowledge, this will be the first study to use an experimental design to examine the effectiveness of a Physiotherapist-led Pilates Intervention for children with hypermobility and pain. Outcome measures will encompass multiple areas of the ICF. It will add to a growing body of evidence of the effect of Pilates for paediatric populations and may provide therapists with alternative management strategies for children with HSD or other musculoskeletal conditions. This information may underpin future intervention studies using larger numbers of children in a RCT design or a SCED at multiple sites. 
A1
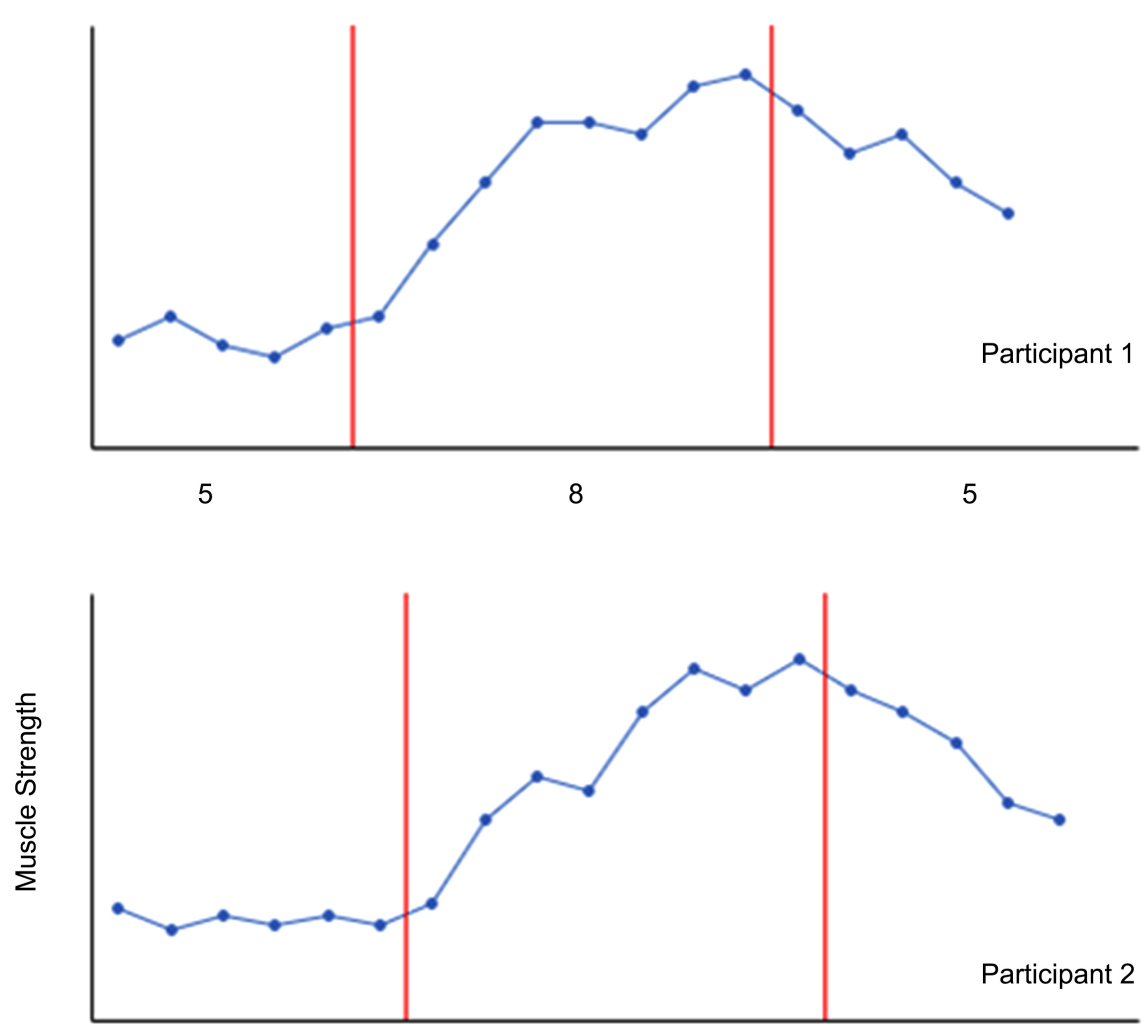

6

8

5

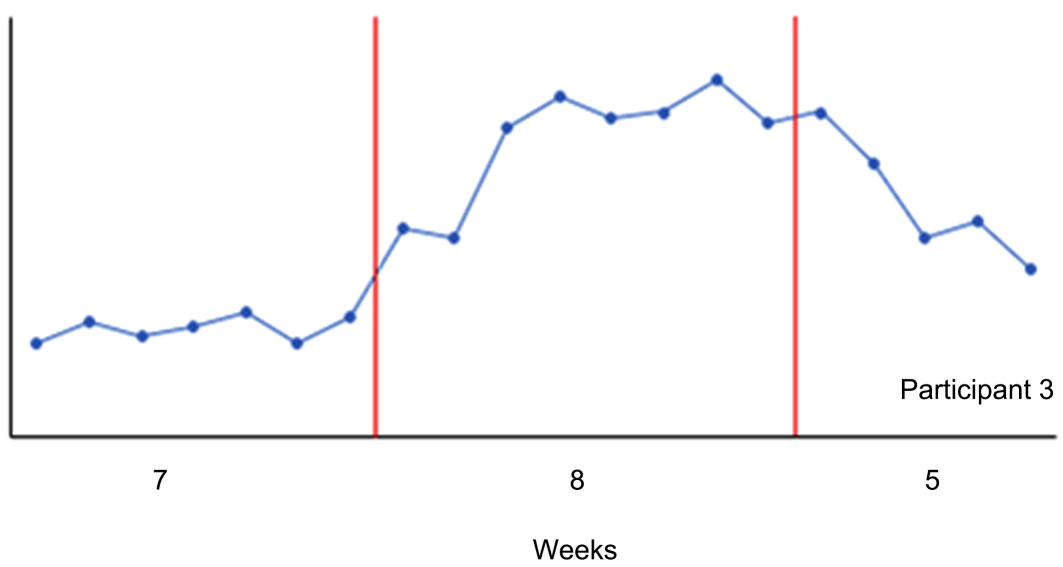

Figure 1. A hypothetical example of the research design: a multiple baseline, single-case experimental design across 3 participants using hypothetical data. The duration of each phase in weeks is plotted on the $\mathrm{x}$-axis, and muscle strength (one of the outcome variables) is plotted on the y-axis. Each of the 3 participants starts in the study concurrently and stays in the base-line phase (A1) from 5 - 7 weeks, is then staggered into the 8-week intervention phase (B1) and continues to stagger into the withdrawal phase (A2). The weekly assessment of muscle strength displays 18 data points for participant 1,19 data points for participant 2 and 20 data points for participant 3. Each transition from one phase to another is denoted by the red line. The data shows stability in the baseline phase (A1), with a hypothesized upward trend in muscle strength during the Pilates Intervention phase (B1) followed by a milder downward trend in the withdrawal phase (A2). 


\section{Acknowledgements}

We would like to thank the Division of Physiotherapy, School of Health and Rehabilitation Sciences, The University of Queensland, Australia who supported this study.

\section{Conflict of Interest}

The authors state that they had no interests that could be perceived as posing a conflict or bias.

\section{References}

[1] Adib, N., Davies, K., Grahame, R., Woo, P. and Murray, K.J. (2005) Joint Hypermobility Syndrome in Childhood. A Not So Benign Multisystem Disorder? Rheumatology, 44, 744-750. https://doi.org/10.1093/rheumatology/keh557

[2] Castori, M., Tinkle, B., Levy, H., Grahame, R., Malfait, F. and Hakim, A. (2017) A Framework for the Classification of Joint Hypermobility and Related Conditions. American Journal of Medical Genetics Part C: Seminars in Medical Genetics, 175, 148-157. https://doi.org/10.1002/ajmg.c.31539

[3] Smits-Engelsman, B., Klerks, M. and Kirby, A. (2011) Beighton Score: A Valid Measure for Generalized Hypermobility in Children. The Journal of Pediatrics, 158, 119-123.e4. https://doi.org/10.1016/j.jpeds.2010.07.021

[4] Clinch, J., Deere, K., Sayers, A., Palmer, S., Riddoch, C., Tobias, J.H. and Clark, E.M. (2011) Epidemiology of Generalized Joint Laxity (Hypermobility) in Fourteen-Year-Old Children from the UK: A Population-Based Evaluation. Arthritis \& Rheumatism, 63, 2819-2827. https://doi.org/10.1002/art.30435

[5] Morris, S.L., O’Sullivan, P.B., Murray, K.J., Bear, N., Hands, B. and Smith, A.J. (2017) Hypermobility and Musculoskeletal Pain in Adolescents. The Journal of Pediatrics, 181, 213-221.e1. https://doi.org/10.1016/j.jpeds.2016.09.060

[6] Lars, R., Dorte, V.J. and Robert, C.W. (2007) Epidemiology of General Joint Hypermobility and Basis for the Proposed Criteria for Benign Joint Hypermobility Syndrome: Review of the Literature. The Journal of Rheumatology, 34, 804-809.

[7] Grahame, R. (2000) The Revised (Brighton 1998) Criteria for the Diagnosis of Benign Joint Hypermobility Syndrome (BJHS). Rheumatology, 27, 1777-1779.

[8] Pilates, J. (1998) Return to Life through Controlology. Presentation Dynamics Inc., Nevada.

[9] Wells, C., Kolt, G.S. and Bialocerkowski, A. (2012) Defining Pilates Exercise: A Systematic Review. Complementary Therapies in Medicine, 20, 253-262. https://doi.org/10.1016/j.ctim.2012.02.005

[10] Muscolino, J.E. and Cipriani, S. (2004) Pilates and the "Powerhouse"-I. Journal of Bodywork and Movement Therapies, 8, 15-24. https://doi.org/10.1016/S1360-8592(03)00057-3

[11] Muscolino, J.E. and Cipriani, S. (2004) Pilates and the "Powerhouse"-II. Journal of Bodywork and Movement Therapies, 8, 122-130. https://doi.org/10.1016/S1360-8592(03)00058-5

[12] Latey, P. (2001) The Pilates Method: History and Philosophy. Journal of Bodywork and Movement Therapies, 5, 275-282. https://doi.org/10.1054/jbmt.2001.0237

[13] Hodges, P.W. and Richardson, C.A. (1997) Relationship between Limb Movement 
Speed and Associated Contraction of the Trunk Muscles. Ergonomics, 40, 1220 1230. https://doi.org/10.1080/001401397187469

[14] Shinkle, J., Nesser, T.W., Demchak, T.J. and McMannus, D.M. (2012) Effect of Core Strength on the Measure of Power in the Extremities. Journal of Strength and Conditioning Research, 26, 373-380. https://doi.org/10.1519/JSC.0b013e31822600e5

[15] Coulombe, B.J., Games, K.E., Neil, E.R. and Eberman, L.E. (2017) Core Stability Exercise versus General Exercise for Chronic Low Back Pain. Journal of Athletic Training, 52, 71-72. https://doi.org/10.4085/1062-6050-51.11.16

[16] Owsley, A. (2005) An Introduction to Clinical Pilates. Athletic Therapy Today, 10, 19-25. https://doi.org/10.1123/att.10.4.19

[17] Behringer, M., vom Heede, A., Yue, Z.Y. and Mester, J. (2010) Effects of Resistance Training in Children and Adolescents: A Meta-Analysis. Pediatrics, 126, e1199e1210. https://doi.org/10.1542/peds.2010-0445

[18] Lloyd, R.S., Faigenbaum, A.D., Stone, M.H., Oliver, J.L., Jeffreys, I., Moody, J.A., et al. (2014) Position Statement on Youth Resistance Training: The 2014 International Consensus. British Journal of Sports Medicine, 48, 498-505. http://dx.doi.org/10.1136/bjsports-2013-092952

[19] Hornsby, E. and Johnston, L.M. (2020) Effect of Pilates Intervention on Physical Function of Children and Youth: A Systematic Review. Archives of Physical Medicine and Rehabilitation, 101, 317-328. https://doi.org/10.1016/j.apmr.2019.05.023

[20] Kamioka, H., Tsutani, K., Katsumata, Y., Yoshizaki, T., Okuizumi, H., Okada, S., et al. (2015) Effectiveness of Pilates Exercise: A Quality Evaluation and Summary of Systematic Reviews Based on Randomized Controlled Trials. Complementary Therapies in Medicine, 25, 1-19. https://doi.org/10.1016/j.ctim.2015.12.018

[21] Mendonça, T.M., Terreri, M.T., Silva, C.H., Neto, M.B., Pinto, R.M., Natour, J., et al. (2013) Effects of Pilates Exercises on Health-Related Quality of Life in Individuals with Juvenile Idiopathic Arthritis. Archives of Physical Medicine and Rehabilitation, 94, 2093-2102. https://doi.org/10.1016/j.apmr.2013.05.026

[22] Alves de Araújo, M.E., da Silva, E.B., Mello, D.B., Ali Cader, S., Salgado, A.S.I. and Dantas, E.H.M. (2011) The Effectiveness of the Pilates Method: Reducing the Degree of Non-Structural Scoliosis, and Improving Flexibility and Pain in Female College Students. Journal of Bodywork and Movement Therapies, 16, 191-198. https://doi.org/10.1016/j.jbmt.2011.04.002

[23] Pacey, V., Tofts, L., Wesley, A., Collins, F. and Singh-Grewal, D. (2014) Joint Hypermobility Syndrome: A Review for Clinicians: Joint Hypermobility Syndrome. Journal of Paediatrics and Child Health, 51, 373-380. https://doi.org/10.1111/jpc.12731

[24] Pacey, V., et al. (2013) Exercise in Children with Joint Hypermobility Syndrome and Knee Pain: A Randomised Controlled Trial Comparing Exercise into Hypermobile versus Neutral Knee Extension. Pediatric Rheumatology, 11, Article No. 30. https://doi.org/10.1186/1546-0096-11-30

[25] Wells, C., Kolt, G.S., Marshall, P., Hill, B. and Bialocerkowski, A. (2014) The Effectiveness of Pilates Exercise in People with Chronic Low Back Pain: A Systematic Review. PLoS ONE, 9, e100402. https://doi.org/10.1371/journal.pone.0100402

[26] da Luz Jr., M.A., Costa, L.O.P., Fuhro, F.F., Manzoni, A.C.T., Bastos, N.T.O. and Cabral, C.M.N. (2014) Effectiveness of Mat Pilates or Equipment-Based Pilates Exercises in Patients with Chronic Nonspecific Low Back Pain: A Randomized Controlled Trial. Physical Therapy, 94, 623-631. https://doi.org/10.2522/ptj.20130277

[27] Backman, C.L., Harris, S.R., Chisholm, J.-A.M. and Monette, A.D. (1997) SingleSubject Research in Rehabilitation: A Review of Studies Using AB, Withdrawal, 
Multiple Baseline, and Alternating Treatments Designs. Archives of Physical Medicine and Rehabilitation, 78, 1145-1153. https://doi.org/10.1016/S0003-9993(97)90142-8

[28] Kratochwill, T.R., Hitchcock, J.H., Horner, R.H., Levin, J.R., Odom, S.L., Rindskopf, D.M., et al. (2012) Single-Case Intervention Research Design Standards. Remedial and Special Education, 34, 26-38. https://doi.org/10.1177\%2F0741932512452794

[29] Zhan, S. and Ottenbacher, K.J. (2001) Single Subject Research Designs for Disability Research. Disability and Rehabilitation, 23, 1-8.

https://doi.org/10.1080/09638280150211202

[30] Australia Department of Health (2019) Australian 24-Hour Movement Guidelines for Children and Young People (5-17 years): An integration of Physical Activity, Sedentary Behaviour and Sleep.

https://www.ehealth.gov.au/internet/main/publishing.nsf/Content/4FA4D308272B D065CA2583D000282813/\$File/Australian\%2024\%20Hour\%20Guideline\%20Devel opment\%20Report\%20for\%20Children\%20and\%20Young\%20people.pdf

[31] World Health Organization (2007) International Classification of Functioning, Disability, and Health: Children \& Youth Version: ICF-CY. World Health Organization, Geneva.

[32] Varni, J.W., Thompson, K.L. and Hanson, V. (1987) The Varni/Thompson Pediatrie Pain Questionnaire. I. Chronic Musculoskeletal Pain in Juvenile Rheumatoid Arthritis. Pain, 28, 27-38. https://doi.org/10.1016/0304-3959(87)91056-6

[33] Sherman, S.A., Eisen, S., Burwinkle, T.M. and \& Varni, J.W. (2006) The PedsQL ${ }^{\mathrm{mm}}$ Present Functioning Visual Analogue Scales: Preliminary Reliability and Validity. Health and Quality of Life Outcomes, 4, Article No. 75.

https://doi.org/10.1186/1477-7525-4-75

[34] Jensen, M.P., Johnson, L.E., Gertz, K.J., Galer, B.S. and Gammaitoni, A.R. (2013) The Words Patients Use to Describe Chronic Pain: Implications for Measuring Pain Quality. Pain, 154, 2722-2728. https://doi.org/10.1016/j.pain.2013.08.003

[35] Dewar, R., Claus, A.P., Tucker, K., Ware, R. and Johnston, L.M. (2017) Reproducibility of the Balance Evaluation Systems Test (BESTest) and the Mini-BESTest in School-Aged Children. Gait \& Posture, 55, 68-74.

https://doi.org/10.1016/j.gaitpost.2017.04.010

[36] James, W.V., Tasha, M.B. and Ilona, S.S. (2004) The PedsQL Multidimensional Fatigue Scale in Pediatric Rheumatology: Reliability and Validity. The Journal of Rheumatology, 31, 2494-2500.

[37] Varni, J.W., Burwinkle, T.M., Seid, M. and Skarr, D. (2003) The PedsQL ${ }^{\mathrm{Tm}} 4.0$ as a Pediatric Population Health Measure: Feasibility, Reliability, and Validity. Ambulatory Pediatrics, 3, 329-341. https://doi.org/10.1367/1539-4409(2003)003\%3C0329:TPAAPP\%3E2.0.CO;2

[38] Voss, C. and K.C. Harris (2017) Physical Activity Evaluation in Children with Congenital Heart Disease. Heart, 103, 1408-1412. http://dx.doi.org/10.1136/heartjnl-2017-311340

[39] Barlow, D. (2009) Single Case Experimental Designs. Strategies for Studying Behaviour Change. 3rd Edition, Pearson, Boston.

[40] Portney, L. (2020) Foundations of Clinical Research-Applications to EvidenceBased Practice. 4th Edition, F. A. Davis Company, Philadelphia.

[41] Barker, J.B., Mellalieu, S.D., McCarthy, P.J., Jones, M.V. and Moran, A. (2013) A Review of Single-Case Research in Sport Psychology 1997-2012: Research Trends and Future Directions. Journal of Applied Sport Psychology, 25, 4-32. 
https://doi.org/10.1080/10413200.2012.709579

[42] Nikles, J. and Mitchell, G. (2015) The Essential Guide to N-of-1 Trials in Health. Springer Netherlands, Dordrecht. https://doi.org/10.1007/978-94-017-7200-6

[43] Perdices, M. and Tate, R.L. (2009) Single-Subject Designs as a Tool for EvidenceBased Clinical Practice: Are They Unrecognised and Undervalued? Neuropsychological Rehabilitation, 19, 904-927. https://doi.org/10.1080/09602010903040691

[44] Smith, J.D. (2012) Single-Case Experimental Designs: A Systematic Review of Published Research and Current Standards. Psychological Methods, 17, 510-550.

https://doi.apa.org/doi/10.1037/a0029312 